\title{
Presepsin ve COUID 19: Literatürün Gözden Geçirilmesi
}

\author{
Presepsin and COVID 19: Review of the Literature \\ Sevil Alkan ${ }^{1}$ (D) Emel Yıldız iD, Havva Yasemin Cinpolat ${ }^{3}$ (D), Serpil Oğuz Mızrakçı ${ }^{\text {id }}$ \\ 1 Enfeksiyon Hastalıkları ve Klinik Mikrobiyoloji Anabilim Dalı, Çanakkale Onsekiz Mart Üniversitesi Tıp Fakültesi, Çanakkale/Türkiye \\ 2 Anestezi ve Reanimasyon Anabilim Dalı, Kütahya Sağlık Bilimleri Üniversitesi Evliya Çelebi Eğitim ve Araştırma Hastanesi, Kütahya/Türkiye \\ 3 Tıbbi Biyokimya Anabilim Dalı, Çanakkale Onsekiz Mart Üniversitesi Tıp Fakültesi, Çanakkale/Türkiye \\ 4 Enfeksiyon Hastalıkları ve Klinik Mikrobiyoloji Bölümü, Özel Lara Anadolu Hastanesi, Antalya/Türkiye
}

\section{özeT}

Koronavirüs hastalığı (COVID-19) hastalığı global olarak mortalite ve morbiditeye neden olmaya devam etmektedir. Hastalığın gerek önlenmesi gerek prognozunun belirlenmesi gerek de patofizyolojisinin anlaşılması konularında bilimsel araştırmalar devam etmektedir. Biyo-belirteçlerin de hastalık patofizyolojinin anlaşılmasında gözde araştırma başlıklarındandır. Presepsin de bu biyobelirteçlerden olup, kritik COVID-19 vakalarının erken tespitinde ve mortalite riskinin değerlendirmesinde kullanılabileceği iddia edilmiştir. Biz de çalışmamızda Koronavirüs COVID-19 ve presepsin ilişkisini literatür eşliğinde irdelemeyi amaçladık. Sınırlı sayıdaki bilimsel makale mevcut olup, mevcut veriler kısıtlı hasta sayılarını içermektedir. Sonuç olarak presepsinin COVID 19 da kullanılabilecek bir biyomarker olduğu konusunda henüz kesin bilimsel kanıtlar bulunmamaktadır. Daha fazla hastayı içeren ileriye dönük çalışmalara intiyaç duyulmaktadır.

Anahtar Kelimeler: COVID 19, presepsin, biyomarker

\section{ABSTRACT}

Coronavirus disease (COVID-19) continues to cause mortality and morbidity globally. Scientific researches continue on the prevention of the disease, determining its prognosis, and understanding its pathophysiology. Biomarkers are also popular research topics in understanding the pathophysiology of the disease. Presepsin is one of these biomarkers and it has been claimed that it can be used in the early detection of critical COVID-19 cases and the assessment of mortality risk. Our study aimed to examine the relationship between coronavirus COVID-19 and presepsin in the light of the literature. A limited number of scientific articles are available, and the available data include a limited number of patients. As a result, there is no definitive scientific evidence yet that presepsin is a biomarker that can be used in COVID 19. Prospective studies with more patients are needed.

Key Words: COVID 19, presepsin, biomarker

\section{GiRiş}

Presepsin diğer ismi ile 'soluble cluster of differentiation CD 14 alt tipi (sCD14-ST;64 amino asit, 13 kDa) çözünebilen CD14'ten türetilen küçük bir peptit olup 2004 yılında yeni bir biyo-belirteç olarak tanımlanmıştır (1). Fagositlere ek olarak, hepatositlerin CD14 salgılayabildiği bildirilmiştir. CD14 kanda proteazlar tarafından bölünerek, SCD14 alt tipi (SCD14-ST) veya presepsin olarak bilinen 64 amino asit kalıntısının kesik bir formunu oluşturabilir (2-5). CD14, lipopolisakkarit-lipopoli-sakkarit bağlayıcı protein (LPS-LBP) komplekslerinin reseptörüdür. Thioinositol lipit yapısı yardımıyla molekülün karboksil terminali hücre zarına tutunur ve endotoksin sinyalini* Toll benzeri reseptör-4 (TLR-4) üzerinden iletir (6). LPS-LBP kompleksinin bir reseptörü olarak CD14, bir dizi sinyal transdüksiyon yolunu ve inflamatuvar kaskadları aktive edebilir ve sistemik inflamatuvar yanıta yol açabilir (7).

Presepsin, $T$ ve $B$ hücreleri ile etkileşerek immün cevabı düzenler. Bu biyo-belirtecin sepsisin erken tanı ve prognozunun öngörülmesinde yüksek bir duyarlılığa ve özgüllüğe sahip olduğu bildirilmiştir (1). Diğer biyobelirteçlerle karşılaştırıldığında, presepsin, sepsis tanısında daha iyi bir duyarlılık ve özgüllüğe sahip gibi görünmektedir. Presepsinin, plazma konsantrasyonunun enfekte hastalarda enfekte olmayan hastalara göre anlamlı derecede daha yüksek olduğu çeşitli çalışmalarda bildirilmiştir (8,9). Zhang ve ark. tarafından yapılan bir metaanaliz çalışmasında 11 çalışma değerlendirilmiştir (10). Bu

\footnotetext{
Yazışma Adresi/Address for Correspondence: Sevil Alkan, MD, Barbaros Mahallesi Prof.Dr.Sevim Buluç Sokak Terzioğlu Yerleşkesi, A Blok 2/4, Çanakkale/Türkiye

E-Posta/E-Mail: s-ewil@hotmail.com || Tel: +90 5066873768

Received/Geliş Tarihi: 09.06.2021 || Accepted/Kabul Tarihi: 24.06.2021

Bu Eser Creative Commons Atıf-Gayriticari 4.0 Uluslararası Lisansı İle Lisanslanmıştır. This work is licensed under a Creative Commons

Attribution-NonCommercial 4.0 International License (CC BY-NC 4.0).
} 
meta-analiz sonucuna göre; presepsinin, sepsis tanısı için etkili bir yardımcı biyo-belirteç olduğu, ancak tek başına kullanıldığında sepsisi saptamak veya dışlamak için yetersiz olduğu sonucuna varılmıştır. Başka bir çalışmada ise; akut solunum sıkıntısı sendromu (ARDS) varlığında, kısa vadeli mortalite için güçlü bir prognostik belirteç olabileceğini gösterilmiştir (11).

Presepsinin birçok çalışmada sepsisin tanısında kullanılabileceği, prognoz ve mortalite tayininde kullanılabileceği bildirilmiştir. Bazı çalışmalar ise sepsis tanısında kullanılacağını ancak sepsis ve septik şok ayrımında anlamlı fark tespit edilemediğini bildirmişlerdir (12-14).

Çağımızın pandemisi Yeni Koronavirüs Hastalığı (COVID-19) global olarak mortalite ve morbiditeye neden olmaya devam etmektedir. Hastalığın gerek önlenmesi gerek prognozunun belirlenmesi gerek de patofizyolojisinin anlaşılması konularında bilimsel araştırmalar devam etmektedir. Presepsin de bu biyo-belirteçlerden olup, kritik COVID-19 vakalarının erken tespitinde ve mortalite riskinin değerlendirmesinde kullanılabileceği öne sürülmüştür (1519). Presepsin pnömoni tanısında, hastalığın sepsis ve septik şoka gidişatını tahmin etmede özellikle diğer biyobelirteçlerle birlikte değerlendirildiğinde gerek erişkin gerek çocuk hastalarda kullanılabileceğini gösteren çalışmalar da mevcuttur (20-22). Ülkemizde yapılan bir çalışmada, kronik obstrüktif akciğer hastalığının (KOAH) akut alevlenmesi ile başvuran hastalarda eşlik eden pnömoniyi saptamada presepsinin rolü araştırılmıştır. KOAH'a eşlik eden pnömoni akut alevlenmesi olan hastalarda; eritrosit sedimantasyon hızı, C-Reaktif Protein (CRP), prokalsitonin ve presepsin değerlerinde istatistiksel olarak anlamlı fark olduğu saptanmıştır. Bu bulgular KOAH akut alevlenmesi olan hastalarda pnömoni tanısında presepsinin kullanılabileceği şeklinde yorumlanmıştır (20).

$\mathrm{Bu}$ çalışmalardan yola çıkılarak, presepsinin COVID-19 pnömonisinde de tanı ve prognoz tayininde kullanılabileceği düşünülebilir. Biz de çalışmamızda COVID-19 ve presepsin ilişkisini literatür eşliğinde irdelemeyi amaçladık.

\section{Literatürün Gözden Geçirilmesi}

Bugüne kadar yayınlanan presepsin ve COVID-19 konulu bilimsel yayınlar incelendi. Makaleler taranırken belirli bir dönem kısıtlaması yapılmadı. PubMed, Medline (Ovid), AMED (Ovid), CINAHL (EBSCO), Scopus ve Web of Science veritabanları " Presepsin" veya "soluble cluster of differentiation CD 14 " ve COVID-19" veya " SARS COV2 " anahtar kelimeleri kullanılarak tarandı. Yapılan literatür taraması sonucunda sadece dört makaleye rastlandı $(17,19,23,24)$.

Japonya'dan Fukada ve ark. (23) tarafından yayınlanan, altı hastadan oluşan vaka serisinde; presepsinin klinisyenlerin yüksek riskli COVID-19 hastalarının tanımlamasına ve erken bir aşamada tedavi stratejilerini belirlemesine olanak tanıdığını ve şiddetli COVID-19 pnömonisi için bir biyolojik belirteç olma potansiyeline sahip olduğunu bildirilmiştir. Bu çalışma retrospektif vaka serisi olup, hafif ve şiddetli COVID19 hastaları arasında hastalığın klinik özelliklerini ve COVID19'un şiddetini değerlendirmek amaçlı; tam kan sayımı ve presepsin dahil serum biyokimyasal belirteçlerden (CRP, PCT ve Krebs von den Lungen-6 (KL-6) yararlanılmıştır. WBC, lenfosit ve trombosit sayıları dahil olmak üzere serum biyokimyasal belirteçlerinin çoğunun, hafif ve şiddetli COVID-19 grupları arasında hiçbir fark göstermediği, presepsin (referans aralığı: 59 to $250 \mathrm{pg} / \mathrm{mL}$ ) ve CRP'nin orta-şiddetli grupta hafif gruptakilere göre başvuru sırasında daha yüksek olduğu saptanmıştır. Ancak bu çalışma sadece altı hasta değerlendirilmiştir.

Yetmiş beş servis ve yoğun bakım ünitesinde (YBÜ) yatan mikrobiyolojik olarak kanıtlı COVID-19 hastasının dahil edildiği bir başka çalışmada, presepsin değerlerinin ölen altı hastada istatistiksel olarak anlamlı yüksek olduğu saptanmıştır. Hastanede yatış sırasında (yatıştan 2-7 gün sonra) presepsin ölçümü, ölen hastalarda Mann-Whitney testi ile yapılan analizde, istatistiksel olarak anlamlı daha yüksek değerlerde saptanmıştır (medyan, IQR = 1047, 7631240; 417, 218-679 ng/L, p<0.05). ROC eğrisi analizine göre, mortaliteyi öngörmede presepsin değerlerinin AUC (ROC Eğrisinin altındaki alan) değeri 0,72'dir $(p<0.05)$. Ayrıca, presepsin ile inflamasyonu yansıtan farklı biyokimyasal parametreler arasındaki Spearman korelasyon testi ile ilişkinin incelenmesinde, CRP $(r=0.59, p<0.001)$, LDH $(r=0.52, p<0.001)$ ile istatistiksel olarak anlamlı ancak zayıf korelasyonlar ve PCT $(r=0.72, p<0.001)$ değerleri ile daha güçlü bağlantı saptanmıştır. Bu korelasyona rağmen, PCT sadece ölen altı hastanın ikisinde (\%33) ve test çalışılan 45 hastanın 11'inde (\%24) 0,5 $\mu \mathrm{g} / \mathrm{L}$ 'den yüksek değerler göstermiştir. Ayrıca, 250 ng/L'den daha yüksek presepsin değeri olan hastaların, daha düşük değerleri olanlara göre (ortalama 17 gün, IQR 12-31; p<0,001) daha uzun bir süre 
YBÜ'de kaldığı bildirilmiştir. Elde edilen veriler, presepsinin COVID-19 hastalarında prognostik bilgi sağlamadaki rolünü göstermiş olup; daha uzun süre hastanede kalmayı ve hastalık şiddetini belirleyebileceği yönündedir. Ancak bu çalışmanın; hastaların ilk başvuru anında ölçülmüş presepsin değerinin olmaması ve sınırlı sayıda ölen hastada değerlendirme yapılmış olması gibi sınırlamaları mevcuttur (24).

Endonezya'dan çocuk COVID 19 hastaları ile yapılan bir çalışmada ise, tüm ölümcül vakalarda prokalsitonin, Ddimer, laktat dehidrojenaz (LDH) ve presepsin seviyelerinin artmış olduğu bildirilmiştir. Bu çalışmada 50 COVID 19 tanısı alan çocuğun 20'si mortal seyretmiştir. Ölüm oranı $\geq 10$ yaş, başvuru sırasında ağır hastalığı olan, $\mathrm{PaO} 2 / \mathrm{FiO} 2$ oranı $\leq 300$ $\mathrm{mmHg}$ ve altta yatan kronik hastalıkları olan hastalarda daha yüksek saptanmıştır. En yaygın klinik belirtiler jeneralize semptomlar iken, akut solunum sıkıntısı sendromu (8/20) ve septik şok (7/20) en yaygın iki ölüm nedeniydi. Ölümcül olguların tamamında başvuru anında ve 3. günde bakılan prokalsitonin, D-dimer, laktat dehidrojenaz ve presepsin düzeylerinde artış saptandığı bildirilmiştir (25).

İki yüz altı çalışmanın analiz edildiği bir meta-analiz çalışmasında ise dışlama kriterleri sonrası sadece 11 çalışma değerlendirilmiştir. Ciddi seyirli COVID-19 hastalarında mortalite belirteçleri olan laboratuvar anormallikleri; beyaz kan hücresi sayısı, nötrofil sayısı, LDH, Alanin aminotransferaz (ALT), Aspartat aminotransferaz (AST), toplam bilirübin, kreatinin, kardiyak troponin, Ddimer, protrombin zamanı (PT), prokalsitonin ve CRP değerlerinde artış ile lenfopeni, hipoalbuminemi olarak saptanmıştır. Presepsin gibi biyo-belirteçlerin ciddi klinik seyir ve mortaliteyi ön görmede kullanılabileceğine vurgu yapılmıştır (26).

Hastaların başvuru anındaki prokalsitonin değerinde önemli ölçüde değişiklik olmadığı, ancak bu değerin giderek artmasının kötü bir prognozu yansıttığı ve kademeli artışı muhtemelen bakteriyel süper enfeksiyonu yansıttığı düşünülmektedir $(26,27)$. Bu da daha sonraki klinik seyrin olumsuz ilerlemesine katkıda bulunabilir. Presepsin gibi diğer yenilikçi sepsis biyo-belirteçlerinin ölçümü, muhtemelen ciddi COVID-19 vakalarının belirlenmesinde doğruluğu artırmanın yanı sıra, ölüm riski tahmini için kullanılan mevcut yaklaşımı iyileştirmeye yardımcı olacağı da savunulmaktadır $(28,29)$.
Birkaç çalışmada ise, presepsinin yalnızca sepsis teşhisi için yararlı olmadığını, aynı zamanda hastalık ciddiyeti ve ölüm oranını da öngördüğünü göstermiştir $(30,31)$. Önceki yıllarda yapılan çalışmalarda presepsinin bakteriyel, fungal ve viral enfeksiyonlarda kullanılabilecek potansiyel bir biyomarker olduğu bildirilmiştir. Ancak COVID-19 ile ilgili veriler sınırlı olup, henüz potansiyel bir biyo-belirteç statüsündedir (23).

\section{SONUÇ}

Sınırlı sayıdaki bilimsel makale mevcut olup, mevcut veriler kısıtlı hasta sayılarını içermektedir. Sonuç olarak presepsinin COVID-19 da kullanılabilecek bir biyomarker olduğu konusunda henüz kesin bilimsel kanıtlar bulunmamaktadır. Daha fazla hastayı içeren ileriye dönük çalışmalara intiyaç duyulmaktadır.

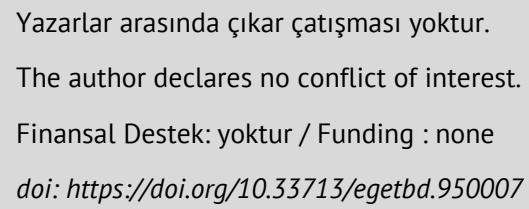

\section{KAYNAKLAR}

1. Zou Q, Wen W, Zhang XC. Presepsin as a novel sepsis biomarker. World J Emerg Med. 2014;5(1):16-19.

2. Meuleman P, Steyaert S, Libbrecht L, Couvent S, Van Houtte $F$, Clinckspoor $F$, et al. Human hepatocytes secrete soluble CD14, a process not directly influenced by HBV and HCV infection. Clin Chim Acta. 2006; 366:156-162.

3. Su GL, Dorko K, Strom SC, Nüssler AK, Wang SC. CD14 expression and production by human hepatocytes. J Hepatol. 1999;31:435-442.

4. Mussap M, Noto A, Fravega M, Fanos V. Soluble CD14 subtype presepsin (SCD14-ST) and lipopolysaccharide binding protein (LBP) in neonatal sepsis: new clinical and analytical perspectives for two old biomarkers. J Matern Fetal Neonatal Med 2011; 24 suppl 2:12-14.

5. Yaegashi $Y$, Shirakawa K, Sato $N$, Suzuki $Y$, Kojika M, Imai S, et al. Evaluation of a newly identified soluble CD14 subtype as a marker for sepsis. J Infect Chemother. 2005; 11:234-238.

6. Gong XW, Jiang Y. Structure, function and modulation of actin-related protein $2 / 3$ complex. Sheng Li Ke Xue Jin Zhan. 2004;35:306-310

7. Yin K, Dang SC, Zhang JX. Relationship between expression of triggering receptor-1 on myeloid cells in intestinal tissue and intestinal barrier dysfunction in severe acute pancreatitis. World J Emerg Med. 2011;2:216-221.

8. Endo S, Suzuki Y, Takahashi G, Shozushima T, Ishikura $H_{\text {, }}$ Murai $A$, et al. Usefulness of perception in the diagnosis of sepsis in a multicenter prospective study. J Infect Chemother. 


\section{2;18:891-897.}

9. JATOS Study Group. Principal results of the Japanese trial to assess optimal systolic blood pressure in elderly hypertensive patients (JATOS) Hypertens Res. 2008;31:2115-2127.

10. Zhang J, Hu ZD, Song J, Shao J. Diagnostic Value of Presepsin for Sepsis: A Systematic Review and Meta-Analysis. Medicine (Baltimore). 2015;94(47):e2158.

11. Zhang $S$, Lin $Q-H$, Shen $L-H$, Wang $P$, Zhang $Z$, Zheng $Y$, et al. Diagnostic value and prognostic evaluation of presepsin for acute respiratory distress syndrome (ARDS). Fudan Univ J Med Sci. 2019; 46:357- 365.

12. Kahveci U, Ozkan S, Melekoglu A, Usul E, Ozturk G, Cetin E, et al. "The role of plasma presepsin levels in determining the incidence of septic shock and mortality in patients with sepsis" J Infect Dev Ctries. 2021; 15(1):123-130. doi:10.3855/jidc.12963.

13. Yamamoto T, Nishimura T, Kaga $S$, Uchida K, Tachibana $Y$, Esaki M, et al. Diagnostic accuracy of presepsin for sepsis by the new Sepsis-3 definitions. Am J Emerg Med. 2019;37: 1936-1941.

14. Mussap M, Puxeddu E, Burrai $P$, Noto A, Cibecchini F, Testa M, Puddu M, Ottonello G, Dessì A, Irmesi R, Gassa ED, Fanni C, Fanos V(2012) Soluble CD14 subtype (sCD14-ST) presepsin in critically ill preterm newborns: preliminary reference ranges. J Matern Fetal Neonatal Med. 2012; 25: 51-53.

15. Arslan B, Sepici Dinçel A. Biyokimya laboratuvarında COVID19: Klinik araştırmadan rutine enflamatuvar belirteçler. Yücel $D$, Editör. COVID-19 Pandemisinde Tıbbi Biyokimyanın Artan Rolü. 1. Baskı. Ankara: Türkiye Klinikleri; 2021. p.13-8.

16. Henry Bm, de Oliveira $\mathrm{mH}$, Benoit $\mathrm{S}$, Plebani M, Lippi $\mathrm{G}$. Hematologic, biochemical and immune biomarker abnormalities associated with severe illness and mortality in coronavirus disease 2019 (COVID-19): a meta-analysis. Clin Chem Lab Med. 2020;58(7):1021-1028.

17. Zaninotto M, Mion MM, Cosma C, Rinaldi D, Plebani M. Presepsin in risk stratification of SARS-CoV-2 patients. Clin Chim Acta. 2020;507:161-163.

18. Tosato F, Giraudo C, Pelloso M, Musso G, Piva E, Plebani M. One disease, different features: COVID-19 laboratory and radiological findings in three Italian patients. Clin Chem Lab Med. 2020;58(7):1149-1151.

19. Schirinzi A, Cazzolla AP, Lovero R, Lo Muzio L, Testa NF, Ciavarella $D$, et al. New Insights in Laboratory Testing for COVID-19 Patients: Looking for the Role and Predictive Value of Human epididymis secretory protein 4 (HE4) and the Innate Immunity of the Oral Cavity and Respiratory Tract. Microorganisms. 2020;8(11):1718.

20. Halıcı A, Hür I, Abatay K, Cetin E, Halıcı F, Özkan S. The role of presepsin in the diagnosis of chronic obstructive pulmonary disease acute exacerbation with pneumonia. Biomark Med. 2020;14(1):31-41.

21. Karakioulaki M, Stolz D. Biomarkers in Pneumonia-Beyond Procalcitonin. Int J Mol Sci. 2019;20(8):2004.

22. Abd Almonaem ER, Rashad MM, Emam HM, El-Shimi OS. Tracheal aspirate presepsin: a promising biomarker in early onset neonatal pneumonia. Scand J Clin Lab Invest. 2021:1-7.

23. Fukada A, Kitagawa $Y$, Matsuoka M, Sakai J, Imai K, Tarumoto $\mathrm{N}$, Orihara $\mathrm{Y}$, et al. Presepsin as a predictive biomarker of severity in COVID-19: A case series. J Med Virol. 2021;93(1):99101.

24. Zaninotto $M$, Mion MM, Cosma C, Rinaldi D, Plebani M.
Presepsin in risk stratification of SARS-CoV-2 patients. Clin Chim Acta. 2020;507:161-3.

25. Dewi R, Kaswandani N, Karyanti MR, Setyanto DB, Pudjiadi $A H$, Hendarto A, et al. Mortality in children with positive SARSCoV-2 polymerase chain reaction test: Lessons learned from a tertiary referral hospital in Indonesia. Int J Infect Dis. 2021;107:78-85

26. Lippi G, Plebani M. Laboratory abnormalities in patients with COVID-2019 infection. Clin Chem Lab Med. 2020;58(7):1131-1134.

27. Lippi G, Plebani M. The novel coronavirus (2019-nCoV) outbreak: think the unthinkable and be prepared to face the challenge. Diagnosis (Berl). 2020;7:79-81.

28. Cervellin G, Schuetz P, Lippi G. Toward a holistic approach for diagnosing sepsis in the emergency department. Adv Clin Chem. 2019;92:201-216.

29. Lippi G. Sepsis biomarkers: past, present and future. Clin Chem Lab Med 2019;57:1281-1283.

30. Endo S, Suzuki $Y$, Takahashi G, Shozushima T, Ishikura $H$, Murai A, et al. Usefulness of presepsin in the diagnosis of sepsis in a multicenter prospective study. J Infect Chemother. 2012; 18: 891- 897.

31. Masson $S$, Caironi $P$, Spanuth $E$, Thomae $R$, Panigada $M$, Sangiorgi G, et al. Presepsin (soluble CD14 subtype) and procalcitonin levels for mortality prediction in sepsis: data from the albumin Italian outcome sepsis trial. Crit Care. 2014; 18: R6.

32. Lin MF, Sun B, Liu ZY, Tang P, Zhang LJ, Wang YY. Evaluation of the clinical diagnostic value of traditional inflammatory markers and novel biomarkers in intracellular bacterial bloodstream infections. Cytokine. 2020;136:155238. doi: 10.1016/j.cyto.2020.155238.

33. Demirpençe Ö, Doğan HO, Erşan $S$, Şahin $M$, Şahin $H$, Bakır M. Presepsin Levels of Patients with Crimean-Congo Hemorrhagic Fever. Jpn J Infect Dis. 2016;69(6):505-509.

34. Stoma I, Karpov I, Uss A, Krivenko S, Iskrov I, Milanovich N, et al. Combination of sepsis biomarkers may indicate an invasive fungal infection in haematological patients. Biomarkers. 2019;24(4):401-406.

35. Bamba Y, Moro H, Aoki N, Koizumi T, Ohshima Y, Watanabe $S$, et al. Increased presepsin levels are associated with the severity of fungal bloodstream infections. PLoS One. 2018;13(10):e0206089. doi: 10.1371/journal.pone.0206089. 